\title{
A Central Role of Moral Obligations in Determining Intentions to Engage in Digital Piracy
}

\author{
Matthew J. Hashim \\ mhashim@email.arizona.edu \\ University of Arizona \\ Department of MIS \\ P.O. Box 210108 \\ Tucson, AZ 85721
}

\author{
Karthik N. Kannan \\ kkarthik@purdue.edu \\ Purdue University \\ Department of Management \\ 403 W. State Street \\ West Lafayette, IN 47907
}

\author{
Duane T. Wegener \\ wegener.1@osu.edu \\ Ohio State University \\ $100 \mathrm{H}$ Lazenby Hall \\ 1827 Neil Ave. \\ Columbus, $\mathrm{OH} 43210$
}

\begin{abstract}
Piracy is a significant source of concern facing software developers, music labels, and movie production companies, to name a few. Digital goods producers and government entities argue that there are victims of piracy, whereas pirates may perceive their actions to be victimless. Regarding implications of our research, we extend the theory of planned behavior (TPB) by theorizing that attitudes, subjective norms, and perceived behavioral control could influence perceptions of moral obligations as a consequence of the desire to rationalize unethical behavior. Unlike prior literature, we manipulate the rationalization of moral obligations due to the victimless view towards piracy, and show how moral obligations become important determinants of piracy behavior. Accordingly, our demonstrated malleability of morals may be an important path through which individuals are able to continue past behaviors. We also conduct a second study to identify the effect of implementing an educational message from a fictitious software company to exogenously nudge the pirate and influence the impact of perceived moral obligations on intentions to pirate. Our results show that the introduction of an exogenous educational message is an effective piracy mitigation strategy.
\end{abstract}

Key words: piracy, morals, victimless crime, theory of planned behavior 
Matthew J. Hashim is an Assistant Professor of Management Information Systems at the Eller College of Management, University of Arizona. He received his Ph.D. in Management with a specialization in MIS from the Krannert School of Management, Purdue University. His research primarily uses experimental and behavioral economics to understand information security problems such as information privacy, digital piracy, password security, social engineering, and other security-related topics. His research has been published in premier journals such as Journal of Management Information Systems and Information Systems Research, and his research has been presented at major conferences and workshops.

Karthik N. Kannan is the Thomas Howatt Chaired Professor of Management at the Krannert School of Management, Purdue University. He received his Ph.D. in information systems from the Heinz College of Public Policy at Carnegie Mellon University. Kannan researches and teaches aspects related to "Designing for Human Instincts." Specifically, he is interested in understanding and designing systems -- products, processes, or policies -- that exploit human instincts and biases in order to nudge behavior. He is a Jefferson Science Fellow for 2017-2018, CERIAS Fellow, and Krannert Faculty Fellow. His research has been published in Journal of Management Information Systems, Management Science, Information Systems Research, MIS Quarterly, and other premier business and economics journals. He serves or has served as an Associate Editor for Management Science, Information Systems Research, and MIS Quarterly.

Duane T. Wegener is a Professor of Social Psychology and Decision Psychology at Ohio State University. He received his Ph.D. in Social Psychology from Ohio State University. His research focuses on attitudes and persuasion, especially influences on the amount and nature of information processing and the consequences of the resulting attitudes for later thinking and behavior. Wegener received the American Psychological Association (APA) Early Career Award for distinguished contributions to the science of social psychology. His research has been published in Journal of Personality and Social Psychology, Advances in Experimental Social Psychology, Journal of Consumer Psychology, Psychological Methods, and other premier journals. He serves or has served as a Section Editor for the Social and Personality Psychology Compass, and Associate Editor for Basic and Applied Social Psychology and the Personality and Social Psychology Bulletin. 


\section{INTRODUCTION}

Digital piracy — defined as the unauthorized copying or use of copyrighted digital goods—is widely believed to be on the rise, fueled by the expansion of access to the Internet and increases in piracy sophistication, among other factors (e.g., torrents, subscription sharing, decreasing costs of storage). Some developers have quantified piracy rates as large as $90 \%$ by using nonmalicious "phoning home" technology [16], and even the emergence of subscription models has not stemmed music piracy as an estimated $20 \%$ of Internet users access music using unlicensed sources [51]. Despite concerns about the growth of piracy and the knowledge of piracy as immoral—or if not immoral, illegal $[28,41,71]$ — pirates widely consider their actions as victimless.

There are many possible reasons contributing to the view of piracy as victimless. For example, the ease of engaging in the behavior and the small magnitude of impact from individual actions both help corroborate the perceived victimless view towards those harmed by piracy as reported in popular press [87], blogs [63,96], and academic research [19,49]. In fact, the perception of piracy as a victimless crime is held by more than $84 \%$ of the subjects we surveyed in our research. ${ }^{i}$ Further, prior research has shown that many pirates do not believe their actions are ethically wrong $[32,65]$, and they engage in the behavior without remorse $[32,84]$. However, limited prior academic research has considered the rationalization by pirates of their behavior as victimless. In this paper, we develop a theoretical model to account for the victimless perspective of piracy and address the following two research questions. First, can our model explain the rationalization of the immoral action of engaging in piracy? Second, once we have established that rationalization of piracy behavior occurs, is it possible to moderate intentions to engage in the behavior, thereby nudging individuals away from piracy? 
To answer our first research question, we extend the well-known theory of planned behavior (TPB), which is extensively used to model intentions to engage in a behavior. In the standard TPB, an individual's attitude, subjective norms, and perceived behavioral control are constructs that influence intentions. Our model accounts for the influence of perceptions of piracy as victimless in explaining a consumer's purchase or pirate decision by including moral obligations in addition to the standard constructs of the TPB. The malleability of morals $[69,76,89]$ allows the pirates to rationalize piracy as victimless even though engaging in the behavior is immoral / illegal. Therefore, we posit a central role for perceived moral obligations as a mediator in the TPB to account for effects of the individual's attitude, subjective norms, and perceived behavioral control towards the piracy decision. We validate our new model by surveying college students about their intentions to engage in music piracy. Our empirical results offer support for the mediating role of perceived moral obligations, providing evidence of the victimless perspective that allows morals to be malleable. The malleability in turn allows those engaging in the behavior to overcome any cognitive dissonance created from knowing that piracy is immoral / illegal.

As regards our second research question, we conduct an additional study to show how moral adjustments may be moderated—and therefore nudged—-through educational communication to individuals. We motivate our exploration of a moderating effect arising from educational messages after observing substantial industry efforts to convert pirates towards becoming purchasers. For example, industry has attempted to educate pirates by creating awareness of the consequences of rationalizing piracy as a victimless crime, suggesting that piracy leads to cascading effects such as job losses and loss of tax revenue, etc. [87]. In fact, the cascading effects of the so-called victimless behavior of engaging in piracy are believed to be 
quite substantial. The U.S. Governmental Accountability Office (GAO) has acknowledged major economic impacts from piracy, as well as obvious difficulty in quantifying piracy rates [72,97]. Industry reports appear to reinforce this acknowledgment, claiming that content providers suffer substantial monetary losses due to piracy. For example, an estimated $43 \%$ of commercial software installations are pirated, valued at approximately $\$ 62.7$ billion [14]. The concern is not limited to just software, as losses due to music piracy are also substantial, estimated at $\$ 12.5$ billion in recent years [50]. Therefore, we introduce an educational message about the impacts of piracy to act as a moderating effect on the path between moral obligations and intentions to engage in piracy.

The prior piracy literature has suggested the existence of the moderating effect we introduce to our model, but it has not to our knowledge been explored in a controlled study or experiment $[42,48,71]$. To provide an example of the approach implemented by our study in practice, producers of an electronic gaming company called 2D Boy speak openly about piracy with the user community and educate their consumers about piracy through the use of usergenerated content such as blog postings and participation in discussion and support forums [16]. Said another way, some firms are consciously pursuing a nudging approach to combat the victimless view towards piracy. Note also, 2D Boy are not alone in their effort in pursuing education and awareness for mitigating piracy that we motivate here, aiding in the generalizability of the approach. Other digital goods industry producers, advocates, and responsible parties have also used similar techniques [77]. Overall, we find a significant moderating effect of an educational message on intentions to engage in software piracy, providing direction and support for an approach that may be pursued in practice to counter malleability of morals due to the victimless view towards piracy. 


\section{RELATED LITERATURE}

Our paper relates to different streams of research in information systems (IS), social psychology, and economics. There are a couple of main differences between our paper and the existing literature. We account for the perception of committing piracy as a victimless crime, and do so using the extended TPB for dishonest actions [10]. Second, because of the perception of piracy as a victimless crime, we also focus on moral aspects of piracy. Given these distinctions, we next survey the related literature.

\section{Theories Related to Behavioral Aspects of Piracy}

Anecdotal evidence treating piracy as a victimless crime, along with contradicting claims regarding the importance of morals in the piracy context, suggests the need to develop a model to better explain the moral aspects of piracy behavior. In order to accomplish that, we draw upon the existing literature related to behavioral aspects of piracy.

The original TPB — as proposed by Ajzen [1,2] — has been utilized widely in the literature to study intentions and predict behavior under various scenarios, and is an extension to the theory of reasoned action (TRA) [3]. Along with the TRA, the original TPB suggested that the key predictor of behavior is intentions to engage in the behavior. Also, within each theory, intentions are predicted by individuals' attitudes toward the behavior (i.e., overall evaluations of the behavior as relatively good or bad) and subjective norms (i.e., perceptions that important others would want the person to behavior in a certain way). The TPB added the notion that perceptions of behavioral control (i.e., ability to enact the behavior) can influence the intentions as well as determine whether the intentions direct the behavior (see [5] for a review).

In the context of piracy, Chang [17] demonstrated that the TPB predicts unethical behavior better than the TRA. The TPB has also been shown to be superior to the Hunt-Vitell 
ethical decision model in predicting piracy intentions [100]. Furthermore, consistent with [17], Peace et al. [75] used the TPB in conjunction with deterrence and expected utility theories to explain the intention to commit software piracy. Our paper is different from their work both in the focus as well as the model employed. Peace et al. [75] mainly focused on antecedent factors leading one to commit software piracy. From the model standpoint, [75] employed the original TPB proposed by Ajzen $[1,2]$ whereas we draw upon the extended TPB from Beck and Ajzen [10], which was specifically developed to account for dishonest and/or illegal actions, and is described below. We also develop a new role for moral obligations that differs from that in [10]. Further, we use a sequence of scenarios to prime piracy as a salient prior behavior. In doing so, we activate the desire to be consistent with the past piracy behavior, especially because of the concept of piracy as a victimless crime.

\section{Morals}

In the context of piracy, the role of morals has been presented in contradictory manners. Moores and Chang [71] developed an adaptation of the moral development model [78], applied it to software piracy, and recommended an ethics training program. In a similar vein, Tan [90] also demonstrated the usefulness of including moral factors (such as moral intensity, moral judgment, and perceived risks) in the piracy context by using an issue-risk-judgment model. In an extended TPB, Cronan and Al-Rafee [28] and also Yoon [99] show that moral obligations should be included as a predictor of intentions to engage in piracy. However, and in contrast to these previously mentioned studies, Logsdon et al. [62] concluded that piracy is perceived to be of low moral intensity because pirates have a high level of tolerance for deviant behavior and do not feel guilt for their actions. Thong and Yap [91] made a similar argument regarding the possible inability of pirates to feel guilt, providing evidence that an ethical decision is influenced by 
factors other than morals. Also, Chen et al. [21] consider both moral intensity and moral judgment as joint moderators in a TPB model under piracy, and find that moral perspectives do have some effect on intentions to engage in piracy.

Perhaps the malleability of morals [69] is the reconciliation between the contrasting positions in the literature. In order to account for the malleability of morals, we begin by including the morals measures from the extended TPB by Beck and Ajzen [10]. Perceived moral obligations in the extended TPB includes measures for guilt, personal principles, and whether or not a particular behavior is considered morally wrong. The measures jointly capture both deontological (moral norms) and utilitarian (guilt due to external consequences) views of ethical decision making. Our inclusion of morals in this context is consistent with Rivis et al. [80], a TPB meta-analysis study that demonstrates the significance of including moral norms as a predictor of intentions for morally-salient behaviors. It is also consistent with Cronan and AlRafee [28], who included moral obligations in a manner similar to Beck and Ajzen [10]. Details about how morals are included in our model are presented in the Research Model and Design Section. We also examine how previous behavior can influence the role of morals in predicting future intentions to pirate.

\section{Sampling, Pricing, and Legal Influences on Piracy}

Regardless of the model employed, we also need to consider the influences of pricing, sampling, and legal issues on piracy behavior. Prior research have shown that high prices and desire to sample a product affect the intention to engage in piracy. The importance of the cost of the software and the desire to sample in software piracy decisions have been demonstrated both empirically $[12,22,34,85]$ and analytically $[11,40,55,61]$. Some of these papers also concluded that sampling creates an opportunity for a future purchase [20]. Sampling in particular is 
important when considering the conversion decision by pirates to become paying customers, and has not always been included in the prior behavioral research. We therefore included design features to control the effects of the desire to sample as well as perceived costs of digital goods in our model. We also considered the legal ramifications of engaging in piracy, however, research has shown that many pirates believe that "there is little or no fear of prosecution for downloading music illegally" [32,84]. Further, the Beck and Ajzen [10] model we implement for our paper has been used to examine not only dishonest, but also illegal actions (i.e., shoplifting), which we explore in the next section of the paper.

\section{RESEARCH MODEL AND DESIGN}

Ajzen [1] identifies attitudes, perceived behavioral control, and subjective norms as the three most salient constructs that predict intention to engage in a behavior. In the piracy context, the prior literature has already hypothesized these relationships $[21,28,75,99]$. To summarize briefly, a favorable attitude towards engaging in piracy implies positive benefits to the pirate; favorable beliefs by one's peers towards piracy reinforce the perception of social pressure supporting piracy; and a greater perceived ability to engage in piracy increases the intentions to engage in piracy. So, restating those justifications is not our focus.

In addition to the three aforementioned constructs, moral obligations has been shown to be a significant predictor of intentions to pirate $[28,80,86]$. Such a consideration of perceived moral obligations to affect intentions to engage in piracy is consistent with the extent to which one perceives a criminal / deviant act to be morally offensive and also create feelings of guilt [10,73]. Consistent with Beck and Ajzen [10], which is a parsimonious model for predicting actions with a moral impact, we also include moral obligations as one of the constructs in our model. In fact, we confine the current research to examining those constructs within the Beck 
and Ajzen [10] TPB model. There has been some precedence in using the same model for predicting intentions to engage in piracy, and the previous literature $[17,28,75,99,100]$ has shown that the TPB is quite useful at predicting piracy intentions, is suitable for decisions involving moral issues, and has better performance in comparison with other models. Also, the Beck and Ajzen [10] TPB model presents itself as an ideal starting point for answering our research questions. That is, the TPB is a straightforward model that can be enhanced to account for the malleability of morals as well as nudging away from piracy intentions (i.e., hypothesizing and testing both mediating and moderating effects). While the model does not include a construct specific to legal concerns (e.g., fear appeals, perceived sanctions), it does include measures that address external consequences. We also considered including other explicit consequences in our study, however, our approach requires implicit justifications of behavior, which we discuss in the next sub-section.

Therefore, we begin our study with the Beck and Ajzen [10] TPB model and include controls such as age, gender, and frequency of piracy which were not considered in the original TPB model. We include these controls in our model because the prior work have shown that older people pirate less than younger people $[4,48,68,71]$; men typically engage in piracy more than women $[28,71]$; and the frequency that an individual has engaged in past piracy has been shown to predict intentions to pirate in the future $[28,99]$. So, to summarize the control variables, we expect that the intention to engage in piracy is decreased for older individuals in comparison with younger individuals, men engage in piracy more than women, and those that have engaged in piracy often in the past will have a higher intention to pirate in the future.

Given that pirates may consider piracy to be a victimless crime, our desire is to develop an enhanced model to accommodate the moral aspects of piracy behavior under the condition of 
piracy as victimless. So, we next consider the primary focus of our research and provide theoretical support for perceived moral obligations as a mediator in the TPB. We draw upon theories of self-concept maintenance, neutralization, moral disengagement, and cognitive dissonance, to build our support, about which we discuss in the following sub-section.

\section{Perceived Moral Obligations as a Mediator}

In the Beck and Ajzen [10] TPB, the perceived moral obligations construct was added to the model to measure feelings of guilt, principles, and moral wrongdoing from engaging in a behavior. In the piracy context, Cronan and Al-Rafee [28] and Yoon [99] hypothesized that moral obligations towards digital piracy will affect intentions to engage in the behavior. That is, engaging in an immoral/illegal behavior such as piracy would trigger feelings of guilt and moral wrongdoing. Therefore, we include the following hypothesis in our model:

Hypothesis 1. Weaker perceived moral obligations towards piracy are positively associated with intentions to engage in piracy.

Piracy has been shown to be viewed as immoral, and if not immoral, illegal. Yet there is a large population that continues to engage in piracy. Neutralization theory has been proposed as a possible explanation to overcome any stigma associated with the immoral act $[64,86]$. Measures implemented by neutralization theory require the survey responders to be explicit about their justification. In piracy, however, such explicit provision of rationale may not occur and often the justifications are implicit. Physiologically, it is believed that when dealing with explicit justifications we utilize reflective processing, whereas we utilize reflexive processing with implicit justifications [82]. So, when explicit justifications are imposed, the need to justify makes the choice primarily driven by reflective processing to be different than when the choice is primarily driven by reflexive processing. The resulting difference in choices has been noted for 
example in the wine-tasting context [70]. For this reason, we believe that it is important to model the implicit justification in the piracy context as well. Below, we discuss a few theories applicable to implicit justifications of piracy.

In general, individuals have a positive view of themselves as: a) competent, b) moral, and c) able to predict their behavior [7]. When engaging in piracy, which they may construe as immoral and/or illegal, they seek to be consistent between their expectations of being moral individuals and their reality of their pirating. According to cognitive dissonance theory, individuals experience discomfort between these inconsistencies, so they seek to reduce their dissonance [35]. One way to do so is for individuals to psychologically enable themselves by justifying their illegal behavior $[64,81]$ by claiming that no harm is introduced by pirating. As noted earlier, pirates attribute the crime to be victimless. The victimless crime notion can also be explained using self-concept maintenance, which is a refinement of cognitive dissonance theory. This theory allows individuals to maintain their self-concept when engaging in behaviors that test their internal standards such as honesty, principles, and moral beliefs [6], by rationalizing their actions. The self-concept is still maintained if, as Mazar et al. [69] suggests, the individuals engage in the behavior without confronting the real meaning of their action. Confronting the real meaning is avoided yet the self-concept is maintained by making morals malleable [69]. Also, individuals maintain their image and shift between acceptable and unacceptable behaviors [76], consistent with the malleability of morals as supported by self-concept maintenance [69]. Therefore, our consideration of the perception of piracy as a victimless crime is a likely cognition that makes morals malleable.

In the piracy context, it is noted that pirates repeatedly engage in such an activity. Therefore, piracy actions can partly be explained by consistency theory $[26,38,47]$, which again 
does not require explicit justification. The theory states that an individual may repeatedly engage in an action, even if morally objectionable, because of the desire to be consistent with previous actions. If the individual does not act in a manner consistent with their previous actions, the resulting inconsistency creates a state of dissonance for the individual. The dissonance motivates the individual to then restore consistency of behavior. That is, individuals may then justify their consistency of behavior by changing their beliefs to align with their past behaviors [15,36]. Arguments regarding consistency of behavior align with our depiction of the malleability of morals when consistent with prior piracy behavior. As such, we expect to observe the malleability of morals if the individual had pirated earlier. ${ }^{\text {ii }}$ Accordingly, in the victimless context of piracy, we posit that moral obligations are influenced by other salient constructs in TPB in a manner that may account for its malleability. The following sections explain how other constructs from the TPB influence morals and intentions to engage in piracy.

\section{Constructs from the Theory of Planned Behavior}

According to the TPB, an individual's perceptions about the benefits of an action affect the individual's engagement in the behavior. In the piracy context, a pirate may perceive many positive benefits, including procuring the focal information good for free, sampling the good without buying, and others $[6,68,75]$. Accordingly, favorable / unfavorable attitudes about piracy are formed that account for the evaluation of the outcomes of engaging in the behavior [1]. When the positive benefits of the behavior increase, pirates face more pressure and temptation to engage in the action. The pressure increases the need to rationalize the immoral behavior and thereby resolve the cognitive dissonance. The rationalization is feasible as piracy is viewed as a victimless crime. So, if engaging in the behavior is deemed more favorable by the pirate, then the pirate will allow his / her positive perceptions to influence moral beliefs. 
Hypothesis 2. Favorable attitudes towards piracy are positively associated with weaker perceived moral obligations.

Next, we consider the effect of subjective norms. In the TPB, this construct captures the peer group's acceptance of an individual's actions [1]. In other words, it corresponds to the individual's perception of social pressure. Pirates believe that "everybody else is doing it" [59]. So, the individual believes that his/her peer group is approving of that behavior. The peer group's approval influences actions even when considering moral dilemmas [30,92]. Further, if "everybody else is doing it," the pirates may face social pressure to engage in piracy $[28,52,94,98]$. As the social pressure to pirate increases, so does the need to make the morals malleable and rationalize their actions. Doing so resolves the dissonance that is created by engaging in the immoral behavior. Accordingly, moral beliefs become weakened to justify conformance due to peer expectations about engaging in piracy.

Hypothesis 3. Favorable subjective norms towards piracy are positively associated with weaker perceived moral obligations.

Following that, we consider the effect of perceived behavioral control. Behavioral control corresponds to the ease or difficulty in performing the behavior, as well as the control over engaging in the behavior [1]. When perceived behavioral control increases, the cognitive load to engage in that action decreases. Also, when an individual's cognitive load increases, prior work has already shown that it decreases even the intention to engage in dishonest action [93]. Conversely, the decrease in cognitive load should increase their intention to engage in piracy. This behavior again leads to an individual rationalizing his / her immoral behavior. The victimless perception only further decreases the cognitive load to pursue the pirating action, which are also consistent with Bandura et al. [9] and Detert et al. [33]. 
Hypothesis 4. Favorable perceived behavioral control about the ability to engage in piracy is positively associated with weaker perceived moral obligations.

\section{Mediation Effects}

Finally, we propose the combined set of research hypotheses to complete our mediated model. Hypotheses 1-4 provide the bases of the model. We combine those hypotheses with the existing predictions for each construct of the TPB affecting intentions to engage in piracy (previously discussed at the beginning of the section). We propose that attitudes, subjective norms, and perceived behavioral control each influence intentions to engage in piracy, but that each of these relationships are mediated by perceived moral obligations. More specifically, we previously argued that favorable views for each of the TPB constructs towards piracy are positively associated with weaker perceived moral obligations. Therefore, to complete the mediation, weaker perceived moral obligations towards piracy are positively associated with intentions to engage in piracy.

Hypothesis 5. The relationship between attitudes towards piracy and intentions to engage in piracy is mediated by perceived moral obligations.

Hypothesis 6. The relationship between subjective norms towards piracy and intentions to engage in piracy is mediated by perceived moral obligations.

Hypothesis 7. The relationship between perceived behavioral control about the ability to engage in piracy and intentions to engage in piracy is mediated by perceived moral obligations.

[Figure 1 about here.]

In summary, we believe that piracy might be viewed as having fewer negative consequences (and, therefore, as facing weaker moral obligations) when the person's attitudes, subjective norms, and perceived behavioral control support (fail to oppose) piracy. In other 
words, people who initially feel some moral compunction at pirating a digital good might shift their perceptions of moral obligations to purchase, especially after engaging in piracy and if attitudes, subjective norms, the perceived ability to pirate, or all three are favorable towards piracy. Our proposed model illustrating perceived moral obligations as a mediator is formalized in Figure 1.

\section{Questionnaire Development}

As highlighted earlier, one of the key contributions of our paper is the further extension of the TPB model proposed by Beck and Ajzen [10] for dishonest and/or illegal actions. Although their model included a measure of actual behavior, we did not include that measure in our setup. The use of intention instead of the actual measure of an illegal activity is consistent with the literature $[17,31,43,75]$. Also, intentions are used because of both practical constraints and because there is a strong relation between intention and behavior in many domains $[5,56]$. Further, engaging in digital piracy is an illegal activity, and even if we included the measure, it is quite likely to be biased. Perhaps, subjects participating in the study may alter their behavior in order to avoid being tracked while performing the illegal activity. Additionally, evidence of actual illegal behavior may expose research participants to a greater amount of risk than is necessary to perform our study. For the same reasons, we also did not implement a longitudinal study to examine piracy over time, and are unable to measure the causal relation between intention and actual behavior.

The subjects were presented with two hypothetical scenarios in which they are interested in acquiring a music album. One scenario describes an initial purchase of the music album (i.e., the individual does not have a copy of the album), and the other scenario describes a conversion purchase of the music album (i.e., the individual already has a pirated copy of the album and is 
faced with a decision to purchase the same). Given the desire to acquire the music album, we consider intentions that range from purchase to pirate only (i.e., doing nothing is not an option we consider). We chose to consider this range of intentions in particular because these are the key actions that are important to copyright holders. We used multiple items to measure each of the constructs in our scenarios. We based our measures on previously validated scales and techniques. Peace et al. [75] as well as Yoon [99] had already modified TPB-related items for the piracy context, and we followed their approach to modify items for the music context.

We presented all subjects with both of the hypothetical scenarios as they symbolize the stages of piracy in which real consumers may find themselves. Unlike the prior literature, we not only used two scenarios, but we also presented the hypothetical scenarios in a particular order. Specifically, subjects received a conversion scenario first, followed by an initial purchase scenario second. The order of the scenarios is critical for manipulating implicit justifications of piracy because the order initiates the desire for consistency of behavior by priming the subject as having already participated in piracy, as discussed in the prior sub-section. Although presenting the scenarios in the reverse order would be comparable to the prior work, it would not allow us to observe the malleability of morals. Therefore, our approach for manipulating consistency of behavior differentiates our research in contrast to prior piracy work.

We also carefully designed the study to control motivations to sample as well as assumptions about pricing, by including instructions at the beginning of the survey and within each scenario. The cost of the music album was described as being affordable to the subject if they chose to purchase it, making the price relative to each subject. We also indicated to subjects within each scenario that they did not need to sample before making their purchase decision by stating they had already enjoyed listening to the music album. 
After responding to the intention questions for both scenarios, survey respondents were then presented with measures from each construct in the TPB (including perceptions of moral obligations). We concluded the survey by asking participants for their gender, age, and frequency of engaging in piracy, as these are considered essential demographic controls for an individual's intention to purchase or pirate as already discussed. All survey questions other than the subject's gender and age were presented as a Likert-type scale ranging between 1 and 7 . Please see the Online Appendix for a sample of the questionnaire.

We sampled undergraduate students at the University of Arizona. College students as a target group are representative of the population that tends to engage in digital piracy $[44,48,60,68]$, and are prominent consumers of digital music. Surveys were distributed electronically during fall semester with students representing various concentrations across the management school (e.g., accounting, finance, information systems, marketing, economics, organizational behavior, etc.). A small number of students from other academic areas such as engineering, liberal arts, or science may also have been included. Subjects were made aware that their responses to the survey would be recorded anonymously and confidentially. Out of 249 surveys completed, 240 were retained. Nine surveys were found after further review to be substantially incomplete, and therefore dropped from the sample.

\section{ANALYSIS}

In this section, we first present the implementation of our theoretical model, followed by the analysis of the reliability of the data, and finally the PLS analysis using WarpPLS 6.0. We configured WarpPLS to use a linear inner model analysis algorithm and specified bootstrapping using 500 resamples for calculating the standard errors. ${ }^{\text {iii }}$ We recognize that prior work $[23,45,66,67]$ have identified some potential concerns with the implementation of PLS in certain 
contexts and have proposed guidelines for the use of PLS in theory development research. ${ }^{\text {iv }}$ In our analysis, we followed those guidelines to ensure the validity of our results.

\section{Measurement and Structural Model}

All intention responses were scaled between 1 and 7, where 1 corresponded to a lower intention to pirate, and 7 corresponded to a higher intention to pirate. Regarding the measure for Frequency of Piracy, 1 corresponded to never and 7 corresponded to daily. Adjustments for reverse coding were made when necessary to be consistent across measures, and those measures needing adjustment are noted in the Online Appendix.

Multivariate tests for reliability and validity of our data and measures are described below. Our examination of the measurement model provided evidence that all of the constructs except subjective norms are measured with three or more highly-interrelated items. The measure for subjective norms had two highly-related items, as the third item did not correlate as highly with the other two items. We also excluded B4 from the analysis for the same reason. ${ }^{\mathrm{v}}$

[Table 1 about here.]

We conducted several multivariate tests to verify convergent validity, discriminant validity, and internal consistency in our measures before conducting our PLS path analyses. Descriptive statistics are shown in Table 1 and provide the mean, standard deviation, minimum, and maximum for each item in each construct. We then generated the results for the final set of analyses using WarpPLS and present them in Tables 2 and 3. Table 2 provides normalized unrotated loadings and promax oblique rotated cross-loadings for the reflective constructs in our model. Loadings are higher on the theoretically assigned constructs as shown by the bold-faced values, than the cross-loadings on the other constructs. Further, the items load on their respective constructs and the $p$-values for the outer model loadings are significant $(p<0.001)$, and establish 
convergent validity in our measures [39]. Although we present normalized unrotated loadings and promax oblique rotated cross-loadings in Table 2, results are consistent across unrotated and rotated approaches, so those analyses are omitted for brevity.

[Table 2 about here.]

[Table 3 about here.]

The bold-faced values in Table 3 represent the square root of the average variance extracted (AVE). The AVE for each construct is much larger than any correlation among the other constructs. This fact from Table 3, in addition to the relative lack of cross-loading as shown by Table 2, provide sufficient evidence of discriminant validity in a PLS analysis [39]. Further, the composite reliability (and Cronbach's alpha) in Table 3 is higher than the recommended 0.70 threshold [23,37], providing sufficient evidence of internal consistency of the items. In summary, from these test results, our measures appear to be internally consistent, and demonstrate convergent and discriminant reliability.

\section{Results}

Our refined version of the TPB designates perceived moral obligations as a mediator of influences of attitudes, subjective norms, and perceived behavioral control on intentions. That is, if digital pirates are considering the moral standing of their behavior, three guides for judging that behavior would seem to involve their evaluation of the good (versus bad) nature of the behavior, the extent to which important others would think well (or ill) of them, and their perceived ability to engage in digital piracy.

[Table 4 about here.]

Table 4 and Figure 2 provide evidence for the primary theoretical contribution of this research. Perceived moral obligations significantly predicts intentions to engage in piracy, 
providing support for Hypothesis 1. Regarding the mediated paths, our results show strong support for perceived moral obligations mediating influences of attitudes, subjective norms, and perceived behavioral control on intention. The significant paths indicate that morals are malleable and are influenced by other constructs, providing support for Hypothesis 2, Hypothesis 3, and Hypothesis 4. Regarding the control variables, women are significantly less likely to engage in piracy that men. Age does not seem to have an effect, and the frequency of piracy has a marginally significant effect in influencing intentions to engage in piracy.

[Figure 2 about here.]

We followed recommendations from the literature to evaluate the mediating effects proposed in our model [58]. First, we utilized standard errors for path coefficients and conducted Sobel tests to assess the significance of the mediating effect of perceived moral obligations for attitudes at $t=4.67, p<0.01$; subjective norms at $t=2.57, p<0.01$; and perceived behavioral control at $t=2.97, p<0.01$. As can be noted by the significant mediation results just presented compared to the results presented in Table 4, the path originating with attitudes is partially mediated through perceived moral obligations, whereas the other two paths are fully mediated. We also evaluated indirect effects sizes, and observed the indirect effect on intentions through perceived moral obligations for attitudes (effect size of $0.214, p<0.01$ ), subjective norms (effect size of $0.062, p<0.01$ ), and perceived behavioral control (effect size of $0.075, p<0: 01$ ). As suggested by the observed effect sizes, the statistically significant indirect effect for attitude on intentions is considered between medium and large, whereas the statistically significant indirect effects for subjective norms and perceived behavioral control on intentions are between small and medium [24,27]. Each of these results provides support for the set of mediating effects, Hypotheses 5-7. 
Further, our model explained more than half of the variance measured for each of the endogenous constructs. That is, perceived moral obligations has an $R^{2}=0.57$, and intention has an $R^{2}=0.53$. We also note that the explained variance is high, and the standardized coefficients are of reasonably large magnitude and significant at $p<0.01$. Also, many of the paths have coefficients $>0.20$, which has been argued to be of potentially meaningful magnitude [23]. Overall, the results provide evidence that individuals may be choosing to rationalize their victimless crime, thereby allowing their morals to be influenced by other constructs from the TPB.

We also evaluated the model for predictive validity and Goodness of Fit (GoF). The Stone-Geisser $Q^{2}$ [95] for the endogenous constructs in the model is 0.566 for perceived moral obligations and 0.535 for piracy intention. Both values are greater than zero, indicating good predictive validity. Per Wetzels et al. [95], we calculated the geometric mean of the average communality and $R^{2}$ values (i.e., Tenenhaus GoF), resulting in a GoF of 0.686 , which is well above the suggested cutoff of 0.36 for large effect sizes. Both results indicate that our mediated model has good predictive validity and model fit.

\section{Tests for Potential Sources of Bias}

We discuss three potential sources of bias in our results in the sub-sections that follow. First, we address the potential for bias due to common method variance (CMV) because our subjects completed the survey questions at one time. CMV may be an issue because our measurement is at the individual level and therefore the subject may bias their responses due to the common method being used. Second, we discuss the use of manipulation checks to provide evidence of the appropriateness of the approach taken to invoke consistency of behavior in our subjects. Finally, we considered concerns about the cost of digital music. As with any human research 
study, our sample consists of subjects of varying financial capacity. Therefore, we designed cost controls into the survey instructions to purposely reduce the possibility for misinterpretation, ${ }^{\mathrm{vi}}$ and accordingly diminish the potential for bias in our results.

\section{Common Method Variance}

We reviewed the recommendations set forth by Bagozzi [8] as well as some more recent work by Chin et al. [25], to assess the extent of common method variance (CMV) in our study. First, we examined our correlation matrix shown in Table 2 in order to identify highly correlated constructs, and we did not find evidence suggesting significant CMV [74]. Second, we implemented the measured latent marker variable (MLMV) approach, as described in Chin et al. [25]. We used construct level corrections (CLC) for the MLMV approach, by including a construct for formal sanctions (severity of punishment), as described and tested by D'Arcy et al. [31]; Siponen et al. [86]. Overall, the potential for CMV to impact the results in our study was shown to be minimal. The marker variable construct correlated on average with the other latent constructs at less than $r=0.10$, providing an estimated impact from CMV at $1 \%$. Coefficients for the structural paths in the MLMV model did not decrease by more than 0.02 , reinforcing the minimal impact of CMV in our study.

\section{Manipulation Checks}

We assessed the manipulation of consistency of behavior at the conclusion of the study. After reading the scenarios, we asked the subjects their opinion about how they felt in regards to having unauthorized copies of a music album. Regarding hypothetical scenario 1 (i.e., the scenario that primed the subject as previously engaged in piracy), $85.5 \%$ of subjects felt the scenario made them feel like they had an unauthorized copy of a music album. Hypothetical scenario 2 (i.e., the scenario was regarding a new purchase) followed with $77.1 \%$ of subjects 
claiming the scenario did not make them feel like they had an unauthorized copy of a music album. Therefore, we believe it is reasonable to expect that the implementation of a staged approach for the order of the scenarios was successful. That is, the order of the scenarios manipulated the belief that subjects were pirating in the first scenario, and then not pirating in the second scenario. The order of the scenarios primed the subjects with feelings to be consistent with—and therefore justify—-their prior behavior.

\section{Overcoming the Malleability of Morals: Testing a Moderating Effect}

Given the strong support for our extended TPB shown by the prior sub-sections (and summarized by Table 4), we conducted a second study that introduces a moderating effect to address the malleability of morals in the model. The following sub-sections describe the second study, as well as any deviations from the extension of the TPB described in the prior sections of the paper.

\section{Nudging in the Piracy Context}

As discussed, when pirates repeatedly engage in the behavior, a desire to remain consistent with prior piracy influences the pirate's actions. So, a key issue then becomes understanding how to modify the behavior to move away from piracy. To modify behavior, intellectual property (IP) holders and industry groups pursue nudging to increase awareness of the effects of piracy so that the pirate converts to purchase instead (that then continues over time). ${ }^{\text {vii }}$ Specifically, IP holders and industry groups often pursue nudging to convey the benefits of purchasing a digital good, and/or the potential detriments to the company and society from engaging in piracy $[13,29]$. The activities pursued by intellectual property holders can be perceived as nudging and the nature of the message provided for nudging is in the socially positive direction [57,77]. In prior works in behavioral economics and public policy, nudging has been shown to influence behavior in a socially positive direction by modifying norms to be more pro-social [53,54]. Further, the role of 
nudging in inhibiting piracy through education has been recommended by the literature as a method for impacting the behavior $[42,46,48,71]$.

To test the effect of nudging potential pirates away from piracy, we introduce an "AntiPiracy Message" as a construct that moderates the role played by moral obligations on intentions to engage in piracy. As already discussed, engaging in piracy has a clear moral impact, especially when considering the external consequences of engaging in the behavior. According to normactivation theory [83], in order to activate moral norms in the piracy context, the individual must be aware of the consequences of their action, and accordingly take responsibility for the impact on others from engaging in the behavior. Therefore, increasing awareness of the moral consequences of engaging in piracy will moderate the malleability of morals discussed in the prior sections. Along a similar vein, Chen et al. [21] have shown that as the moral intensity of piracy behavior increases, intentions to engage in piracy decrease as a result. Also, ethics researchers have demonstrated the importance of awareness programs in raising the moral consideration within individuals of an organization $[18,88]$, providing additional justification for our approach and the relationship between awareness and morals. Further, effective nudging disrupts the desire to be consistent with prior piracy behavior ('consistency' with prior piracy already described in earlier sections of the paper).

The proposed moderator influences the impact of perceived moral obligations on piracy intentions. Consistent with the literature, and both the practical and theoretical support just discussed, we expect the "Anti-Piracy Message" to moderate the impact of perceived moral obligations on digital piracy intention. Stated formally,

Hypothesis 8. The receipt of a morally-salient message will activate moral obligations about engaging in piracy, moderating (decreasing) the positive relation between an individual's 
weaker perceived moral obligations and their intentions to engage in piracy.

Next, we describe the implementation of the moderator in the second study.

\section{Implementation and Analysis of the Moderating Effect}

We implemented the moderating effect using the same approach as before, but with several specific changes to the questionnaire that account for the moderator and also increase the saliency of piracy occurring in the scenario. First, we changed the context of the hypothetical scenarios from music piracy to software piracy. The rationale for the context change was to increase the perceived magnitude of the piracy impact (i.e., software is generally much more expensive than music). ${ }^{\text {viii }}$ Second, instead of "download an unauthorized copy" we instead used "pirate your own copy". The wording change increases perceptions of piracy as a loaded term, bringing attention to the piracy action as a negative behavior. ${ }^{\mathrm{ix}}$ Third, for a random subset of our sample, an anti-piracy message from a fictitious company selling the software was appended to each hypothetical scenario. By introducing the message, we test the impact of management's ability to nudge a digital pirate's intentions towards becoming a paying customer. The antipiracy (pro-purchase) message stated the following: "Thank you for your interest in XYZ-Soft's software. Your purchase helps the overall software industry, benefits our employees, increases tax revenue, and reduces job loss. Click here to purchase our software from an authorized retailer." Finally, instead of using multi-item dispositional measures to measure intentions, we introduced a situational, single-item dependent measure of likelihood of purchasing a software program instead. We did so because the situational dependent variable is consistent with the timing of the situational "Anti-Piracy Message", whereas a dispositional measure of intention would not be consistent. Finally, we omitted the frequency of piracy question in order to improve our chances of receiving honest responses given the loaded wording (as well as the in-class 
version of the survey described in the next sub-section). None of these modifications affects the theoretical meaning or interpretation of our extended TPB, and allow us to provide a normative contribution to the literature. Further, the changes made to the study are designed only to illustrate one approach to addressing the piracy problem (recommended by Gopal and Sanders [42], Higgins et al. [48], and Moores and Chang [71]), as many approaches are possible.

The second study was conducted at two large universities in the United States. We used an on-line survey at the University of Arizona during spring and fall academic semesters, and we used an in-class survey at Purdue University during spring and summer academic semesters. Subjects from undergraduate IS classrooms were recruited from both locations, prior instructor permission was obtained, voluntary participation was requested but not required, and subjects were aware that their responses to the survey would be recorded anonymously and confidentially. We obtained 70 usable responses from the former university, and 98 usable responses from the latter university, for a total of 168 observations.

\section{Measurement and Structural Model}

Similar to the first study, we conducted several multivariate tests to verify convergent validity, discriminant validity, and internal consistency in our measures for the second study. Descriptive statistics are shown in Table 5 and provide the mean, standard deviation, minimum, and maximum for each item in each construct. Table 6 provides normalized unrotated loadings and promax oblique rotated cross-loadings for the reflective constructs in our model. Consistent with the first study, loadings are higher on the theoretically assigned constructs as shown by the boldfaced values, than the cross-loadings on the other constructs. The items load only on their respective constructs and the $p$-values for the outer model loadings are significant $(p<0.001)$, establishing convergent validity in our measures. 
[Table 5 about here.]

[Table 6 about here.]

Further, the bold-faced values in Table 7 represent the square root of the average variance extracted (AVE) for each construct. The AVE is much larger than any correlation among the other constructs. This fact from Table 7, in addition to the relative lack of cross-loading as shown by Table 6, provide sufficient evidence of discriminant validity. The high composite reliability (and Cronbach's alpha) in Table 7 provide sufficient evidence of internal consistency of the items. In summary, our measures appear to be internally consistent, demonstrate convergent and discriminant reliability, and are consistent with the results presented by our first study.

[Table 7 about here.]

\section{Results}

Similar to the results described for the first study, all hypotheses for the previously hypothesized mediated paths are supported except for the path from perceived behavioral control to intention as illustrated by Table 8 . The second study therefore provides further evidence for the primary theoretical contribution of this research. Regarding the moderating effect, Table 8 shows a negative and significant moderating effect of the anti-piracy message on the impact of perceived moral obligations on purchase intention. The result is in support of Hypothesis 8 . Also, the $\Delta R^{2}$ when the moderating effect is included is 0.04 . Therefore, we find the moderating effect size is

0.06 using Cohen's $f^{2}$, which is between a small and medium effect size (i.e., greater than 0.02 but still less than $0.15[24,27]){ }^{\mathrm{x}}$

[Table 8 about here.]

The moderated model explained more than half of the variance measured for perceived moral obligations $\left(R^{2}=0.53\right)$, and $R^{2}=0.37$ for intention. Again, we note that the explained 
variance in the model is high, and the standardized coefficients for the hypothesized paths (with the exception of PBC) are of reasonably large magnitude with path coefficients $>0.20$, and statistical significance at $p<0.01$. Overall, the results from the moderated model support the results presented earlier, and provide evidence of a significant moderating effect. We do note that although the sign flipped for the path from PBC to PMO in comparison to what we predicted, the magnitude of the coefficient is quite small and could have arisen from the change of context (i.e., software instead of music). For example, downloading and playing music files (e.g., .MP3), is much simpler in contrast to the difficulty in terms of download time and knowledge of computer software, such as copying and installing a software package. Further, specialized and simple to use music sharing applications may also drive the simplicity (e.g., BearShare, KaZaa, LimeWire, Napster, among others), in comparison to more general software applications used for piracy such as uTorrent. Regardless of the source of the change, the meaning of the moderating effect and the model's overall consistency with the first study is unchanged.

As before, we also evaluated the model for predictive validity and Goodness of Fit (GoF). The Stone-Geisser $Q^{2}$ for the endogenous constructs in the model is 0.525 for perceived moral obligations and 0.367 for piracy intention. Both values are greater than zero, indicating good predictive validity. Per Wetzels et al. [95], we calculated the geometric mean of the average communality and $R^{2}$ values, resulting in a GoF of 0.623 , which is well above the suggested cutoff of 0.36 for large effect sizes. Both results indicate that our moderated extension of the mediated model has good predictive validity and model fit.

\section{DISCUSSION AND CONCLUSION}

Digital piracy is a growing and serious problem that affects individuals, businesses, and governmental entities. Our study is motivated by a real-world setting and provides a positivist 
contribution to the literature regarding why pirates perceive their actions as victimless crimes.

Our research also allows for greater understanding of the underlying purchase or pirate decision by extending existing theory.

We empirically reinforced our theoretical assertion that perceived moral obligations may be influenced by attitudes, subjective norms, and perceived behavioral control, by including perceived moral obligations as a mediator in our model. Regarding mediation effects, we found empirical support for indirect effects of attitudes, subjective norms, and perceived behavioral control through perceived moral obligations. We believe that the mediation effect of perceptions of moral obligations results from motives to justify past unethical behavior by considering past piracy. Accordingly, our demonstrated malleability of morals may be an important path through which individuals are able to continue past behaviors. Therefore, it is important for managerial decision-makers to be aware of the need to disrupt rationalizations to remain consistent with prior piracy behavior.

In addition to our theoretical extension to the TPB, we also provide a normative contribution by the inclusion of a morally-salient anti-piracy message as a moderator of perceived moral obligations on intention. The introduction of exogenous manipulation such as the anti-piracy message can be used to enhance current forms of educational communication as a piracy mitigation strategy. As such, our research contributes to mitigation strategies by countering the threat of piracy by potential consumers. Further, although we focused on an antipiracy educational message in our study, a message may be adjusted to specific consumer characteristics, associated awareness, and educational needs as necessary.

\section{Practical Implications}

Our study offers several practical implications that may be implemented by managerial decision- 
makers to address the victimless view towards piracy. First, it may be possible to disrupt the malleability of morals by not allowing consumers to rationalize their behavior through disruption of repeated behaviors. Perhaps one method is to make past purchase behavior salient to the consumer, instead of allowing the pirate to focus on their past piracy. Doing so may allow a digital goods producer to break a pattern driven by consistency of bad behavior, thereby increasing the saliency of good behavior. Second, our moderated model has shown that a morally-salient anti-piracy message may be used to increase the effect of moral obligations on intention to purchase. A simple anti-piracy message can be quickly disseminated through social networking, peer-to-peer networks, online discussion forums, and opinion pieces and interviews. Besides the significant results presented in our study, we have also observed anecdotal positive results in practice, as shown by firms such as $2 \mathrm{D}$ Boy. They have used simple, yet seemingly effective anti-piracy messaging on their blog to increase sales of their highly-pirated software program [16].

\section{Limitations and Future Research}

Our research is not without limitations. First, we used reported intentions to engage in piracy instead of measuring actual behavior. However, prior related studies have found reported intentions to be reliable predictors of actual behavior. Also, reported intentions are a preferred design choice for our study due to the illegality of piracy in the United States, and our desire to limit subjects' exposure to risk from engaging in illegal activities. We also limited our research to digital music for the first study and software for the second study, but did not consider digital video or other information goods. We believe our choice of context for the first study was appropriate for our population, and is also representative of a multi-billion dollar music industry. Although we cannot make the claim that the results from our study would be generalizable to 
such contexts as enterprise software and corporate piracy, we are confident that our behavioral model will carry over to other perceived victimless piracy contexts.

Lastly, although our focus was primarily on the mediating effect of moral obligations due to piracy being perceived as victimless, future research could address additional interventions to counter the victimless perception. Such an approach could potentially intervene in a purchase decision, especially given the evidence provided by our second study. Therefore, a strategy of communicating to customers about the negative effects of piracy may be useful, especially if past piracy is salient to the consumer. Future research could also expand our enhanced model to explore the illegality of piracy by capturing additional types of legal concerns beyond those addressed by moral concerns. Also, the dissonance approach of communicating with a consumer that they purchased a previous product to encourage them to purchase a future product has yet to have been explored. Future digital piracy research should consider accounting for consistency of behavior across time (or other motives to rationalize past unethical behavior).

\section{REFERENCES}

1. Ajzen, I. From intentions to actions: A theory of planned behavior. Springer, 1985.

2. Ajzen, I. The theory of planned behavior. Organizational Behavior and Human Decision Processes, 50, 2 (1991), 179-211.

3. Ajzen, I. and Fishbein, M. Understanding attitudes and predicting social behavior. PrenticeHall, Englewood Cliffs, NJ, 1980.

4. Al-Rafee, S. and Cronan, T.P. Digital piracy: Factors that influence attitude toward behavior. Journal of Business Ethics, 63, 3 (2006), 237-259.

5. Armitage, C.J. and Conner, M. Efficacy of the theory of planned behaviour: A meta-analytic review. British Journal of Social Psychology, 40, 4 (2001), 471-499.

6. Aronson, E. The Theory of Cognitive Dissonance: A Current Perspective. Advances in Experimental Social Psychology, 4, C (1969), 1-34.

7. Aronson, E. Review: Back to the future: Retrospective review of Leon Festinger's "A theory of cognitive dissonance.” The American Journal of Psychology, 110, 1 (1997), 127-137.

8. Bagozzi, R.P. Measurement and meaning in information systems and organizational research: Methodological and philosophical foundations. MIS Quarterly, 35, 2 (2011), 261292.

9. Bandura, A., Barbaranelli, C., Caprara, G.V., and Pastorelli, C. Mechanisms of Moral Disengagement in the Exercise of Moral Agency. Journal of Personality and Social 
Psychology, 71, 2 (1996), 364-374.

10. Beck, L. and Ajzen, I. Predicting dishonest actions using the theory of planned behavior. Journal of Research in Personality, 25, 3 (1991), 285-301.

11. Bhattacharjee, S., Gopal, R., Marsden, J.R., Sankaranarayanan, R., and Telang, R. To theme or not to theme: Can theme strength be the music industry's "killer app"? Decision Support Systems, 48, 1 (2009), 141-149.

12. Bhattacharjee, S., Gopal, R.D., and Sanders, G.L. Digital music and online sharing: Software piracy 2.0? Communications of the ACM, 46, 7 (2003), 107-111.

13. Business Software Alliance. Seventh annual BSA/IDC global software: 09 piracy study. 2010.

14. Business Software Alliance. The compliance gap: BSA global software survey. 2014.

15. Campbell, R. and Kumar, V. Moral reasoning on the ground. Ethics, 122, 2 (2012), 273-312.

16. Carmel, R. and Gabler, K. 90\%. 2D Boy, 2008. http://2dboy.com/2008/11/13/90/.

17. Chang, M.K. Predicting unethical behavior: A comparison of the theory of reasoned action and the theory of planned behavior. Journal of Business Ethics, 17, 16 (1998), 1825-1834.

18. Chatterjee, S., Sarker, S., and Valacich, J.S. The behavioral roots of information systems security: Exploring key factors related to unethical IT use. Journal of Management Information Systems, 31, 4 (2015), 49-87.

19. Chellappa, R.K. and Shivendu, S. Economic implications of variable technology standards for movie piracy in a global context. Journal of Management Information Systems, 20, 2 (2003), 137-168.

20. Chellappa, R.K. and Shivendu, S. Managing piracy: Pricing and sampling strategies for digital experience goods in vertically segmented markets. Information Systems Research, 16, 4 (2005), 400-417.

21. Chen, M.-F., Pan, C.-T., and Pan, M.-C. The joint moderating impact of moral intensity and moral judgment on consumer's use intention of pirated software. Journal of Business Ethics, 90, 3 (2009), 361-373.

22. Cheng, H.K., Sims, R.R., and Teegen, H. To purchase or pirate software: An empirical study. Journal of Management Information Systems, 13, 4 (1997), 49-60.

23. Chin, W.W. Issues and opinion on structural equation modeling. MIS Quarterly, 22, 1 (1998), vii-xvi.

24. Chin, W.W., Marcelin, B.L., and Newsted, P.R. A partial least squares latent variable modeling approach for measuring interaction effects: Results from a Monte Carlo simulation study and an electronic-mail emotion/adoption study. Information Systems Research, 14, 2 (2003), 189-217.

25. Chin, W.W., Thatcher, J.B., Wright, R.T., and Steel, D. Controlling for Common Method Variance in PLS Analysis: The Measured Latent Marker Variable Approach. Springer Proceedings in Mathematics and Statistics, 56, (2013), 231-239.

26. Cialdini, R.B. Influence: The Psychology of Persuasion. William Morrow and Company, Inc., New York, NY, 1993.

27. Cohen, J. Statistical Power Analysis for the Behavioral Sciences. Lawrence Erlbaum Associates, Inc., Hillsdale, NJ, 1988.

28. Cronan, T.P. and Al-Rafee, S. Factors that influence the intention to pirate software and media. Journal of Business Ethics, 78, 4 (2008), 527-545.

29. Ćwiakowski, P., Giergiczny, M., and Krawczk, M. Pirates in the lab: Using incentivized choice experiments to explore preference for (un)authorized content. MIS Quarterly, 40, 3 
(2016), 709-715.

30. D’Arcy, J. and Devaraj, S. Employee Misuse of Information Technology Resources: Testing a Contemporary Deterrence Model. Decision Sciences, 43, 6 (2012), 1091-1124.

31. D'Arcy, J., Hovav, A., and Galletta, D. User awareness of security countermeasures and its impact on information systems misuse: A deterrence approach. Information Systems Research, 20, 1 (2009), 79-98.

32. De Corte, C.E. and Van Kenhove, P. One Sail Fits All? A Psychographic Segmentation of Digital Pirates. Journal of Business Ethics, 143, 3 (2017), 441-465.

33. Detert, J.R., Treviño, L.K., and Sweitzer, V.L. Moral Disengagement in Ethical Decision Making: A Study of Antecedents and Outcomes. Journal of Applied Psychology, 93, 2 (2008), 374-391.

34. Douglas, D.E., Cronan, T.P., and Behel, J.D. Equity perceptions as a deterrent to software piracy behavior. Information and Management, 44, 5 (2007), 503-512.

35. Festinger, L. A Theory of Cognitive Dissonance. Row Peterson, Evanston, IL, 1957.

36. Festinger, L. and Carlsmith, J.M. Cognitive consequences of forced compliance. Journal of Abnormal and Social Psychology, 58, 2 (1959), 203-210.

37. Fornell, C. and Larcker, D.F. Evaluating structural equation models with unobservable variables and measurement error. Journal of Marketing Research, 18, 1 (1981), 39-50.

38. Freedman, J.L. and Fraser, S.C. Compliance without pressure: The foot-in-the-door technique. Journal of Personality and Social Psychology, 4, 2 (1966), 195-202.

39. Gefen, D. and Straub, D. A practical guide to factorial validity using PLS-Graph: Tutorial and annotated example. Communications of the AIS, 16, (2005), 91-109.

40. Geng, X. and Lee, Y.-J. Competing with piracy: A multichannel sequential search approach. Journal of Management Information Systems, 30, 2 (2013), 159-184.

41. Goles, T., Jayatilaka, B., George, B., et al. Softlifting: Exploring determinants of attitude. Journal of Business Ethics, 77, 4 (2008), 481-499.

42. Gopal, R.D. and Sanders, G.L. Preventive and deterrent controls for software piracy. Journal of Management Information Systems, 13, 4 (1997), 29-47.

43. Gorsuch, R.L. and Ortberg, J. Moral obligation and attitudes: Their relation to behavioral intentions. Journal of Personality and Social Psychology, 44, 5 (1983), 1025-1028.

44. Gunter, W.D., Higgins, G.E., and Gealt, R.E. Pirating youth: Examining the correlates of digital music piracy among adolescents. International Journal of Cyber Criminology, 4, 1 and 2 (2010), 657-671.

45. Hair, J.F., Ringle, C.M., and Sarstedt, M. PLS-SEM: Indeed a silver bullet. Journal of Marketing Theory and Practice, 19, 2 (2011), 139-151.

46. Hashim, M.J., Kannan, K.N., Maximiano, S., and Ulmer, J.R. Digital Piracy, Teens, and the Source of Advice: An Experimental Study. Journal of Management Information Systems, 31, 2 (2014), 211-244.

47. Heider, F. The Psychology of Interpersonal Relations. Lawrence Erlbaum Associates, Inc., Hillsdale, NJ, 1958.

48. Higgins, G.E., Wolfe, S.E., and Marcum, C.D. Digital piracy: An examination of three measurements of self-control. Deviant Behavior, 29, 5 (2008), 440-460.

49. Ingram, J.R. and Hinduja, S. Neutralizing music piracy: An empirical examination. Deviant Behavior, 29, (2008), 334-366.

50. International Federation of the Phonographic Industry. Digital music report 2009. 2009. http://www.ifpi.org/content/library/DMR2009-real.pdf. 
51. International Federation of the Phonographic Industry. Tackling music piracy. 2017. http://www.ifpi.org/music-piracy.php.

52. Jeong, B.-K., Zhao, K., and Khouja, M. Consumer piracy risk: Conceptualization and measurement in music sharing. International Journal of Electronic Commerce, 16, 3 (2012), 89-118.

53. John, P., Smith, G., and Stoker, G. Nudge nudge, think think: Two strategies for changing civic behaviour. Political Quarterly, 80, 3 (2009), 361-370.

54. Kahan, D.M. Gentle Nudges vs. Hard Shoves: Solving the Sticky Norms Problem. University of Chicago Law Review, 67, 3 (2000), 607.

55. Khouja, M. and Park, S. Optimal pricing of digital experience goods under piracy. Journal of Management Information Systems, 24, 3 (2007), 109-141.

56. Kim, D.J., Ferrin, D.L., and Rao, H.R. A trust-based consumer decision-making model in electronic commerce: The role of trust, perceived risk, and their antecedents. Decision Support Systems, 44, 2 (2008), 544-564.

57. Knopper, S. Rock and Roll: RIAA's campus crackdown. Rolling Stone, 2007, 15.

58. Kock, N. Advanced Mediating Effects Tests, Multi-Group Analyses, and Measurement Model Assessments in PLS-Based SEM. International Journal of e-Collaboration, 10, 1 (2014), 1-13.

59. Levin, D. Guest Column: Rick Chazan on music piracy. Mess + Noise, 2011. http://www.messandnoise.com/features/4172775.

60. Limayem, M., Khalifa, M., and Chin, W.W. Factors motivating software piracy: A longitudinal study. IEEE Transactions on Engineering Management, 51, 4 (2004), 414-425.

61. Liu, Y., Cheng, H.K., Tang, Q.C., and Eryarsoy, E. Optimal software pricing in the presence of piracy and word-of-mouth effect. Decision Support Systems, 51, 1 (2011), 99-107.

62. Logsdon, J.M., Thompson, J.K., and Reid, R.A. Software piracy: Is it related to level of moral judgment? Journal of Business Ethics, 13, 11 (1994), 849-857.

63. Lowery, D. Letter to Emily White at NPR all songs considered. The Trichordist, 2012. https://thetrichordist.com/2012/06/18/letter-to-emily-white-at-npr-all-songs-considered/.

64. Lowry, P.B., Zhang, J., and Wu, T. Nature or nurture? A meta-analysis of the factors that maximize the prediction of digital piracy by using social cognitive theory as a framework. Computers in Human Behavior, 68, (2017), 104-120.

65. Lysonski, S. and Durvasula, S. Digital piracy of MP3s: Consumer and ethical predispositions. Journal of Consumer Marketing, 25, 3 (2008), 167-178.

66. Marcoulides, G.A., Chin, W.W., and Saunders, C. A critical look at partial least squares modeling. MIS Quarterly, 33, 1 (2009), 171-176.

67. Marcoulides, G.A. and Saunders, C. PLS: A silver bullet? MIS Quarterly, 30, 2 (2006), IIIIV.

68. Marshall, A. Causes, effects and solutions of piracy in the computer software market. Review of Economic Research on Copyright Issues, 4, 1 (2007), 63-86.

69. Mazar, N., Amir, O., and Ariely, D. The dishonesty of honest people: A theory of selfconcept maintenance. Journal of Marketing Research, 45, 6 (2008), 633-644.

70. Melcher, J.M. and Schooler, J.W. The misremembrance of wines past: Verbal and perceptual expertise differentially mediate verbal overshadowing of taste memory. Journal of Memory and Language, 35, 2 (1996), 231-245.

71. Moores, T.T. and Chang, J.C.-J. Ethical decision making in software piracy: Initial development and test of a four-component model. MIS Quarterly, 30, 1 (2006), 167-180. 
72. Offutt, S. Insights gained from efforts to quantify the effects of counterfeit and pirated goods in the U.S. economy. United States Government Accountability Office, 2013.

73. Paternoster, R. and Simpson, S. Sanction threats and appeals to morality: Testing a rational choice model of corporate crime. Law and Society Review, 30, 3 (1996), 549-583.

74. Pavlou, P.A., Liang, H., and Xue, Y. Understanding and mitigating uncertainty in online exchange relationships: A principal-agent perspective. MIS Quarterly, 31, 1 (2007), 105135.

75. Peace, A.G., Galletta, D.F., and Thong, J.Y.L. Software piracy in the workplace: A model and empirical test. Journal of Management Information Systems, 20, 1 (2003), 153-177.

76. Piquero, N.L., Tibbetts, S.G., and Blankenship, M.B. Examining the role of differential association and techniques of neutralization in explaining corporate crime. Deviant Behavior, 26, 2 (2005), 159-188.

77. Pyyny, P. MPAA to fund anti-piracy education in schools. AfterDawn, 2003. http://www.afterdawn.com/news/article.cfm/2003/10/24/mpaa_to_fund_antipiracy_education_in_schools.

78. Rest, J.R. Development in Judging Moral Issues. University of Minnesota Press, Minneapolis, MN, 1979.

79. Ringle, C.M., Wende, S., and Will, A. SmartPLS 2.0 (M3) Beta. University of Hamburg, Hamburg, Germany, 2005.

80. Rivis, A., Sheeran, P., and Armitage, C.J. Expanding the affective and normative components of the theory of planned behavior: A meta-analysis of anticipated affect and moral norms. Journal of Applied Social Psychology, 39, 12 (2009), 2985-3019.

81. Rogers, J.W. and Buffalo, M.D. Neutralization techniques: Toward a simplified measurement scale. Sociological Perspectives, 17, 3 (1974), 313-331.

82. Schooler, J.W. Verbalization produces a transfer inappropriate processing shift. Applied Cognitive Psychology, 16, 8 (2002), 989-997.

83. Schwartz, S.H. Normative influences on altruism. Advances in Experimental Social Psychology, 10, C (1977), 221-279.

84. Sinclair, G. and Green, T. Download or stream? Steal or buy? Developing a typology of today's music consumer. Journal of Consumer Behaviour, 15, 1 (2016), 3-14.

85. Sinha, R.K., Machado, F.S., and Sellman, C. Don't think twice, it's all right: Music piracy and pricing in a DRM-free environment. Journal of Marketing, 74, 2 (2010), 40-54.

86. Siponen, M., Vance, A., and Willison, R. New insights into the problem of software piracy: The effects of neutralization, shame, and moral beliefs. Information and Management, 49, $7-$ 8 (2012), 334-341.

87. Smith, E. and Benoit, D. Nine movie sites busted in pirating crackdown. The Wall Street Journal, 2010.

http://online.wsj.com/article/SB10001424052748703426004575339120611859094.html.

88. Smith, N.C., Simpson, S.S., and Huang, C.-Y. Why managers fail to do the right thing: An empirical study of unethical and illegal conduct. Business Ethics Quarterly, 17, 4 (2007), 633-667.

89. Sykes, G.M. and Matza, D. Techniques of neutralization: A theory of delinquency. In Delinquency and Drift Revisited: The Criminology of David Matza and Beyond. 2017, pp. 33-41.

90. Tan, B. Understanding consumer ethical decision making with respect to purchase of pirated software. Journal of Consumer Marketing, 19, 2 (2002), 96-111. 
91. Thong, J.Y.L. and Yap, C.-S. Testing an ethical decision-making theory: The case of softlifting. Journal of Management Information Systems, 15, 1 (1998), 213-237.

92. Treviño, L.K., Weaver, G.R., and Reynolds, S.J. Behavioral ethics in organizations: A review. Journal of Management, 32, 6 (2006), 951-990.

93. Van't Veer, A.E., Stel, M., and van Beest, I. Limited capacity to lie: Cognitive load interferes with being dishonest. Judgment and Decision Making, 9, 3 (2014), 199-206.

94. Wang, J., Yang, Z., and Bhattacharjee, S. Same coin, different sides: Differential impact of social learning on two facets of music piracy. Journal of Management Information Systems, 28, 3 (2011), 343-384.

95. Wetzels, M., Odekerken-Schröder, G., and Van Oppen, C. Using PLS path modeling for assessing hierarchical construct models: Guidelines and empirical illustration. MIS Quarterly, 33, 1 (2009), 177-196.

96. White, E. I never owned any music to begin with. NPR music, 2012. http:/www.npr.org/sections/allsongs/2012/06/16/154863819/i-never-owned-any-music-tobegin-with.

97. Yager, L. Observations on efforts to quantify the economic effects of counterfeit and pirated goods. United States Government Accountability Office, 2010.

98. Yang, Z. and Wang, J. Differential effects of social influence sources on self-reported music piracy. Decision Support Systems, 69, (2015), 70-81.

99. Yoon, C. Theory of Planned Behavior and Ethics Theory in Digital Piracy: An Integrated Model. Journal of Business Ethics, 100, 3 (2011), 405-417.

100. Yoon, C. Digital piracy intention: A comparison of theoretical models. Behaviour and Information Technology, 31, 6 (2012), 565-576.

\section{TABLES AND FIGURES}

Table 1: Descriptive Statistics $(\mathrm{n}=240)$

\begin{tabular}{lccccc}
\hline Demographics & Count & Mean & Std. Dev. & Min & Max \\
\hline Male & 142 & - & - & - & - \\
Female & 97 & - & - & - & - \\
Gender Unknown & 1 & - & - & - & - \\
Age & 239 & 21.98 & 2.72 & 18 & 41 \\
Frequency of Piracy & 239 & 2.53 & 1.67 & Never & Daily \\
\hline \multicolumn{1}{l}{ Construct } & & & & & \\
\hline Attitudes & Items & Mean & Std. Dev. & Min & Max \\
& A1 & 3.52 & 1.17 & 1 & 7 \\
& A2 & 3.87 & 1.24 & 1 & 7 \\
& A3 & 3.65 & 1.25 & 1 & 7 \\
\hline Subjective Norms & A4 & 3.97 & 1.29 & 1 & 7 \\
& N1 & 3.89 & 1.18 & 1 & 7 \\
\hline Perceived Behavioral Control & N2 & 4.59 & 1.61 & 1 & 7 \\
& B1 & 5.08 & 1.68 & 1 & 7 \\
& B2 & 5.40 & 1.56 & 1 & 7 \\
& B3 & 4.31 & 1.68 & 1 & 7
\end{tabular}




\begin{tabular}{lccccc}
\hline Perceived Moral Obligations & M1 & 4.26 & 1.74 & 1 & 7 \\
& M2 & 4.24 & 1.59 & 1 & 7 \\
& M3 & 3.84 & 1.67 & 1 & 7 \\
\hline Intentions & I1 & 4.86 & 1.53 & 1 & 7 \\
& I2 & 4.93 & 1.57 & 1 & 7 \\
& I3 & 5.04 & 1.55 & 1 & 7 \\
\hline
\end{tabular}

Table 2: Loadings and Cross-Loadings

\begin{tabular}{lcccccc}
\hline \multirow{2}{*}{ Construct } & Items & Attitudes & $\begin{array}{c}\text { Subjective } \\
\text { Norms }\end{array}$ & PBC & PMO & $\begin{array}{c}\text { Piracy } \\
\text { Intentions }\end{array}$ \\
\hline Attitudes & $\mathrm{A} 1$ & $\mathbf{0 . 6 1 7}$ & 0.008 & -0.080 & 0.222 & -0.098 \\
& $\mathrm{~A} 2$ & $\mathbf{0 . 6 2 7}$ & -0.065 & -0.102 & -0.186 & 0.148 \\
& $\mathrm{~A} 3$ & $\mathbf{0 . 6 1 1}$ & -0.026 & 0.049 & 0.268 & -0.091 \\
& $\mathrm{~A} 4$ & $\mathbf{0 . 6 1 9}$ & 0.076 & 0.123 & -0.258 & 0.029 \\
\hline \multirow{2}{*}{ Subjective Norms } & $\mathrm{N} 1$ & 0.191 & $\mathbf{0 . 7 4 9}$ & -0.042 & -0.235 & -0.002 \\
& $\mathrm{~N} 2$ & -0.219 & $\mathbf{0 . 6 6 2}$ & 0.048 & 0.269 & 0.003 \\
\hline PBC & $\mathrm{B} 1$ & -0.111 & 0.070 & $\mathbf{0 . 7 3 0}$ & 0.038 & -0.050 \\
& $\mathrm{~B} 2$ & -0.075 & -0.031 & $\mathbf{0 . 7 6 6}$ & 0.034 & 0.023 \\
& $\mathrm{~B} 3$ & 0.346 & -0.065 & $\mathbf{0 . 6 4 9}$ & -0.135 & 0.045 \\
\hline \multirow{2}{*}{ PMO } & $\mathrm{M} 1$ & -0.067 & 0.000 & 0.029 & $\mathbf{0 . 6 0 7}$ & 0.044 \\
& $\mathrm{M} 2$ & 0.036 & -0.004 & 0.000 & $\mathbf{0 . 5 9 8}$ & 0.056 \\
& $\mathrm{M} 3$ & 0.026 & 0.004 & -0.025 & $\mathbf{0 . 6 2 2}$ & -0.091 \\
\hline \multirow{2}{*}{ Intentions } & $\mathrm{I} 1$ & -0.016 & 0.006 & -0.007 & 0.015 & $\mathbf{0 . 9 9 9}$ \\
& $\mathrm{I} 2$ & 0.016 & 0.014 & -0.032 & -0.006 & $\mathbf{0 . 6 4 2}$ \\
& $\mathrm{I} 3$ & 0.000 & -0.021 & 0.040 & -0.008 & $\mathbf{0 . 6 4 6}$ \\
\hline
\end{tabular}

Table 3: Reliability and Interconstruct Correlations

\begin{tabular}{lccccccc}
\hline Construct & $\begin{array}{c}\text { Composite } \\
\text { Reliability }\end{array}$ & $\begin{array}{c}\text { Cronbach's } \\
\text { Alpha }\end{array}$ & Attitudes & $\begin{array}{c}\text { Subjective } \\
\text { Norms }\end{array}$ & PBC & PMO & $\begin{array}{c}\text { Piracy } \\
\text { Intentions }\end{array}$ \\
\hline Attitudes & 0.871 & 0.803 & $\mathbf{0 . 7 9 3}$ & & & & \\
Subjective Norms & 0.874 & 0.712 & 0.550 & $\mathbf{0 . 8 8 1}$ & & & \\
PBC & 0.887 & 0.806 & 0.443 & 0.328 & $\mathbf{0 . 8 5 2}$ & & \\
PMO & 0.940 & 0.904 & 0.716 & 0.521 & 0.484 & $\mathbf{0 . 9 1 6}$ & \\
Intentions & 0.959 & 0.935 & 0.651 & 0.466 & 0.402 & 0.671 & $\mathbf{0 . 9 4 1}$ \\
\hline
\end{tabular}

Note: Boldface items are the square root of the average variance extracted

Table 4: Summary of Hypothesis Tests

\begin{tabular}{ccccc}
\hline Hypothesis & Path & $\boldsymbol{B}$ & Significance & Supported? \\
\hline H1 & PMO $\rightarrow$ Intentions & 0.39 & $p<0.01$ & yes \\
H2 & Attitudes $\rightarrow$ PMO & 0.54 & $p<0.01$ & yes \\
H3 & Subjective Norms $\rightarrow$ PMO & 0.16 & $p<0.01$ & yes \\
H4 & PBC $\rightarrow$ PMO & 0.19 & $p<0.01$ & yes \\
- & Attitudes $\rightarrow$ Intentions & 0.30 & $p<0.01$ & - \\
- & Subjective Norms $\rightarrow$ Intentions & 0.06 & $p=0.17$ & - \\
- & PBC $\rightarrow$ Intentions & 0.04 & $p=0.22$ & -
\end{tabular}




\begin{tabular}{cccc} 
Age $\rightarrow$ Intentions & -0.04 & $p=0.22$ & - \\
Gender $\rightarrow$ Intentions & -0.10 & $p<0.05$ & - \\
Frequency $\rightarrow$ Intentions & 0.07 & $p<0.10$ & - \\
\hline
\end{tabular}

Table 5: Descriptive Statistics for the Moderating Effect Study $(\mathrm{n}=168)$

\begin{tabular}{lccccc}
\hline Demographics & Count & Mean & Std. Dev. & Min & Max \\
\hline Male & 107 & - & - & - & - \\
Female & 60 & - & - & - & - \\
Gender Unknown & 1 & - & - & - & - \\
Age & 166 & 21.95 & 2.86 & 18 & 39 \\
Anti-Piracy Message & 81 & - & - & - & - \\
\hline \multicolumn{7}{l}{ Construct } & & & & & \\
\hline Attitudes & Items & Mean & Std. Dev. & Min & Max \\
& A1 & 3.30 & 1.30 & 1 & 7 \\
& A2 & 3.63 & 1.29 & 1 & 7 \\
& A3 & 3.42 & 1.42 & 1 & 7 \\
Subjective Norms & A4 & 3.86 & 1.52 & 1 & 7 \\
\hline Perceived Behavioral Control & N1 & 3.74 & 1.33 & 1 & 6 \\
& N2 & 4.39 & 1.75 & 1 & 7 \\
\hline Perceived Moral Obligations & B2 & 4.95 & 1.72 & 1 & 7 \\
& M1 & 3.48 & 1.53 & 1 & 7 \\
& M2 & 3.76 & 1.88 & 1 & 7 \\
\hline Intentions & M3 & 3.28 & 1.63 & 1 & 7 \\
\hline
\end{tabular}

Table 6: Loadings and Cross-Loadings for the Moderating Effect Study

\begin{tabular}{|c|c|c|c|c|c|}
\hline Construct & Items & Attitudes & $\begin{array}{c}\text { Subjective } \\
\text { Norms }\end{array}$ & PBC & PMO \\
\hline \multirow[t]{4}{*}{ Attitudes } & A1 & 0.687 & -0.206 & 0.084 & 0.174 \\
\hline & A2 & 0.660 & 0.230 & -0.022 & 0.004 \\
\hline & A3 & 0.693 & -0.136 & -0.027 & 0.054 \\
\hline & A4 & 0.694 & 0.135 & -0.038 & -0.223 \\
\hline \multirow[t]{2}{*}{ Subjective Norms } & N1 & 0.061 & 0.683 & 0.167 & 0.011 \\
\hline & $\mathrm{N} 2$ & -0.051 & $\mathbf{0 . 7 3 7}$ & -0.141 & -0.009 \\
\hline \multirow[t]{3}{*}{$\mathrm{PBC}$} & B1 & -0.036 & 0.018 & 0.869 & 0.034 \\
\hline & B2 & -0.098 & 0.111 & 0.825 & 0.077 \\
\hline & B3 & 0.162 & -0.155 & 0.791 & -0.134 \\
\hline \multirow[t]{3}{*}{ PMO } & M1 & 0.098 & 0.110 & -0.056 & 0.648 \\
\hline & M2 & -0.092 & 0.009 & -0.001 & 0.688 \\
\hline & M3 & 0.021 & -0.086 & 0.041 & 0.696 \\
\hline
\end{tabular}


Table 7: Reliability and Interconstruct Correlations for the Moderating Effect Study

\begin{tabular}{lcccccc}
\hline Construct & $\begin{array}{c}\text { Composite } \\
\text { Reliability }\end{array}$ & $\begin{array}{c}\text { Cronbach's } \\
\text { Alpha }\end{array}$ & Attitudes & $\begin{array}{c}\text { Subjective } \\
\text { Norms }\end{array}$ & PBC & PMO \\
\hline Attitudes & 0.895 & 0.843 & $\mathbf{0 . 8 2 5}$ & & & \\
Subjective Norms & 0.901 & 0.780 & 0.537 & $\mathbf{0 . 9 0 6}$ & & \\
PBC & 0.889 & 0.811 & 0.334 & 0.353 & $\mathbf{0 . 8 5 4}$ & \\
PMO & 0.931 & 0.890 & 0.676 & 0.573 & 0.204 & $\mathbf{0 . 9 0 5}$ \\
\hline
\end{tabular}

Note: Boldface items are the square root of the average variance extracted

Table 8: Summary of Hypothesis Tests for the Moderating Effect Study

\begin{tabular}{ccccc}
\hline Hypothesis & Path & $\boldsymbol{\beta}$ & Significance & Supported? \\
\hline H1 & PMO $\rightarrow$ Intentions & 0.42 & $p<0.01$ & yes \\
H2 & Attitudes $\rightarrow$ PMO & 0.54 & $p<0.01$ & yes \\
H3 & Subjective Norms $\rightarrow$ PMO & 0.32 & $p<0.01$ & yes \\
H4 & PBC $\rightarrow$ PMO & -0.09 & $p<0.10$ & no (sign) \\
H8 & Anti-Piracy Message $\times$ PMO $\rightarrow$ Intentions & -0.21 & $p<0.01$ & yes \\
- & Attitudes $\rightarrow$ Intentions & 0.05 & $p=0.31$ & - \\
- & Subjective Norms $\rightarrow$ Intentions & 0.05 & $p=0.30$ & - \\
- & PBC $\rightarrow$ Intentions & 0.09 & $p=0.13$ & - \\
- & Anti-Piracy Message $\rightarrow$ Intentions & 0.03 & $p=0.31$ & - \\
- & Age $\rightarrow$ Intentions & -0.16 & $p<0.01$ & - \\
- & Gender $\rightarrow$ Intentions & -0.02 & $p=0.39$ & - \\
\hline
\end{tabular}

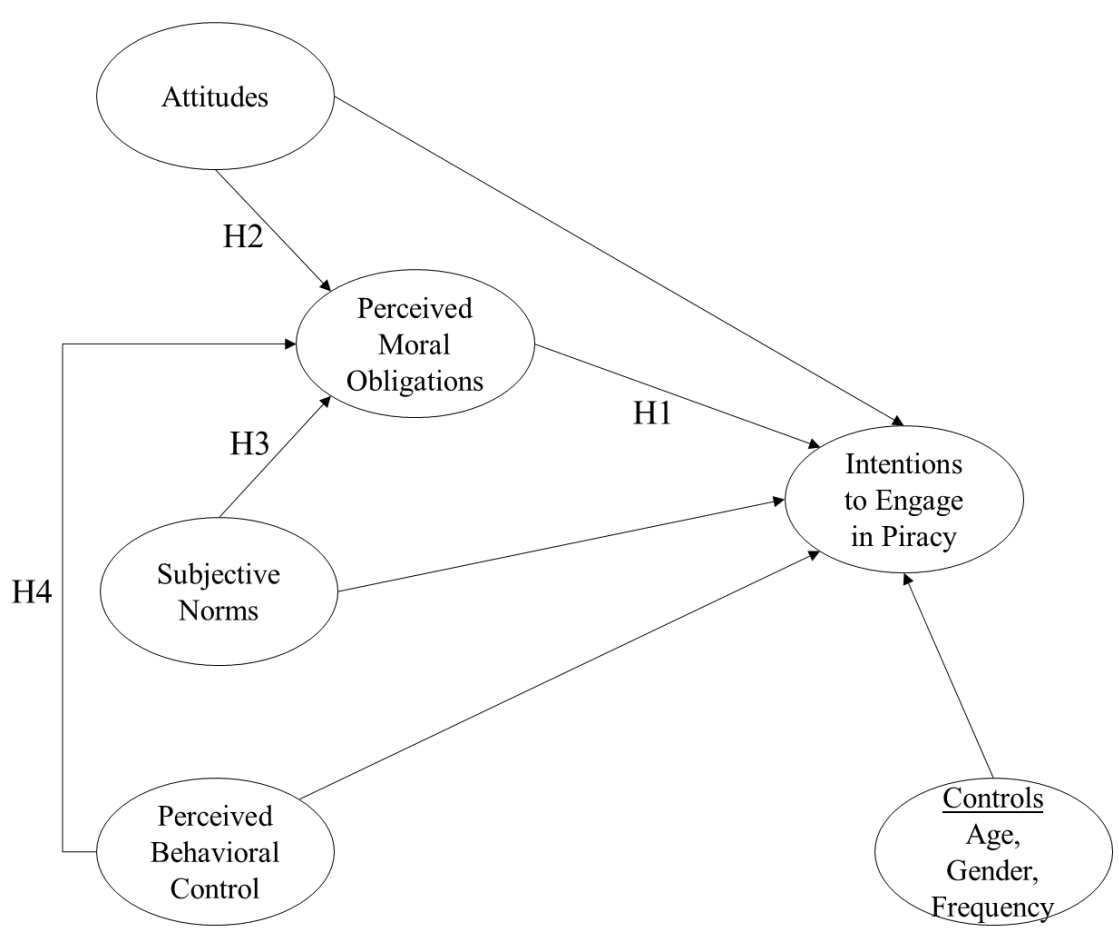

Figure 1: Perceived Moral Obligations as a Mediator in our Refined Theory of Planned Behavior 


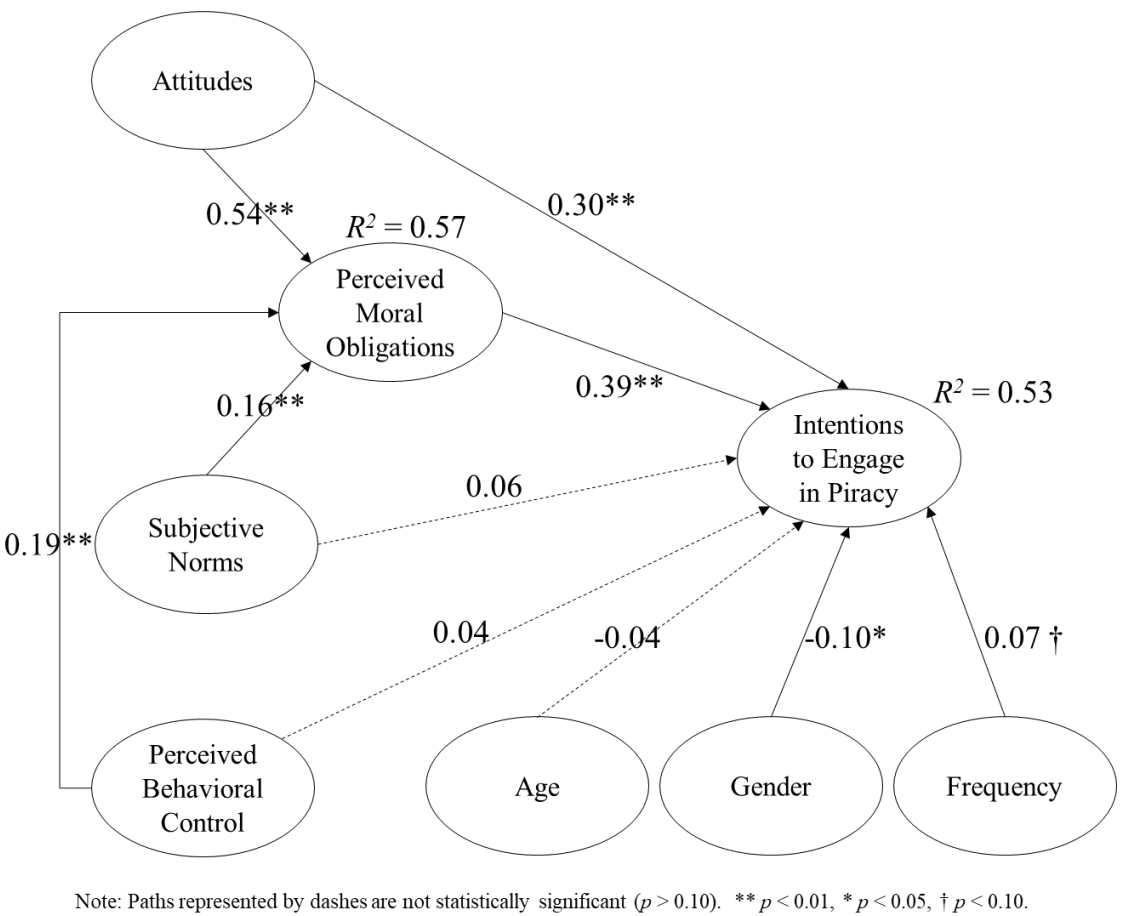

\section{Figure 2: Analysis of Perceived Moral Obligations as a Mediator in our Refined Theory of Planned Behavior}

\footnotetext{
${ }^{\text {i }}$ Please see the Online Appendix for details regarding our questionnaire.

ii We implement a unique procedure using hypothetical scenarios in a questionnaire (see the Questionnaire Development Section for details) to manipulate consistency of behavior.

iii We used SmartPLS 2.0.M3 [79] to conduct construct level corrections to assess the potential impact of common method variance.

iv The literature suggests all PLS analyses should include clear reporting of the statistical analyses conducted, implement a proper use of indicators (i.e., formative vs. reflective), avoid "rule-of-thumb" small sample sizes, ensure and test for proper data quality (e.g., reliability and validity), and report predictive relevance, among others. ${ }^{v}$ Cross-loading of items with other constructs was never observed with N3 and/or B4 included.

vi See the Online Appendix for details.

vii There are potentially two types of effects that may occur: 1) inhibition of new pirated goods, and 2) conversion of existing pirated goods to non-pirated goods. We intentionally do not make a distinction between these two effects.

viii We captured perceptions of cost (based upon Peace et al. [75]) and compared responses between the studies to assess financial impact. Participants reported that the music context was significantly lower in cost in comparison to the software context (two sample $t$-test with unequal variances for music vs. software; means of $4.99 \mathrm{vs.} 5.64 ; t=$ $6.32 ; p<0.001)$. Therefore, we are confident that the participants viewed the software context as having a higher financial impact, and thus higher piracy saliency.

ix We note here that the interpretation of a "loaded" term such as piracy is individually interpreted. That is, some may view piracy as an acceptable activity, whereas others may associate it with an illegal activity.

${ }^{x}$ Cohen's $f^{2}=\left[R^{2}\right.$ (interaction model) $-R^{2}$ (main effects model) $] /\left[1-R^{2}\right.$ (interaction model) $]: f^{2}=(0.36-0.32) /(1-$ $0.36)$.
} 


\section{Online Appendix: \\ A Central Role of Moral Obligations in Determining \\ Intentions to Engage in Digital Piracy}

\section{Survey Instrument}

\section{Notes:}

Each of the measures from the TPB as developed by Beck and Ajzen [10] were slightly modified for our survey instrument. We followed $[28,75,99]$ as those authors had already implemented the TPB items for the piracy context. We either re-used their items exactly, or slightly modified them to remove potentially loaded terms such as 'piracy' or 'pirate'.

1. An asterisk next to a question represents a reverse-coded response.

2. Please refer to Table 1 for the mapping of the construct to the item. I refers to Intention, A to Attitude, $\mathrm{N}$ to Subjective Norms, B to Perceived Behavioral Control, and $\mathrm{M}$ to Perceived Moral Obligations.

3. We do not use the measures from scenario 1 in our analysis. Scenario 1 is presented to the subjects for the sole purpose of priming consistency of behavior as discussed in the Research Model and Design section of the paper.

\section{SURVEY INSTRUCTIONS:}

In this survey you will be presented with hypothetical situations. Please read the hypothetical situations carefully and answer each question in the survey honestly. Your responses to the questions are confidential.

Also, consider the following definition of copied music throughout the survey: "the unauthorized use of another's production, invention, or conception especially in infringement of a copyright."

The following facts apply for each scenario:

1) XYZ-Music is an imaginary musical act or band that you like

2) It would be a stretch financially to afford the music in the scenario, but you could pay for it if you chose to

\section{Hypothetical Scenario 1}

You have an unauthorized copy of a music album in your personal music collection. The music album is by XYZ-Music. You have previously enjoyed listening to the music album and you are now considering purchasing it.

The music album is available for purchase online, or you can continue using the unauthorized copy for free.

I may copy music without paying for it in the future. (Strongly Agree - Strongly Disagree)* If I had the opportunity, I would copy music without paying for it. (Strongly Agree - Strongly 
Disagree)*

I would never copy music without paying for it. (Strongly Agree - Strongly Disagree)

\section{Hypothetical Scenario 2}

You plan to acquire a music album for your personal music collection. The music album is by XYZ-Music. You have previously enjoyed listening to the music album from a friend's music collection but now you want your own copy.

The music album is available for purchase online, or you can download an unauthorized copy for free.

(I1): I may copy music without paying for it in the future. (Strongly Agree - Strongly Disagree)* (I2): If I had the opportunity, I would copy music without paying for it. (Strongly Agree Strongly Disagree)*

(I3): I would never copy music without paying for it. (Strongly Agree - Strongly Disagree)

(A1): To me, making unauthorized copies of music is: (Very Good - Very Bad)*

(A2): To me, making unauthorized copies of music is: (Very Pleasant - Very Unpleasant)*

(A3): To me, making unauthorized copies of music is: (Very Wise - Very Foolish)*

(A4): To me, making unauthorized copies of music is: (Very Attractive - Very Unattractive)*

(N1): If I make unauthorized copies of music, most of the people who are important to me would: (Strongly Approve - Strongly Disapprove)*

(N2): Most people who are important to me would be disappointed with me if I make unauthorized copies of music. (Very Likely - Very Unlikely)

(N3): No one who is important to me thinks it is okay to make unauthorized copies of music.

(Strongly Agree - Strongly Disagree)

(B1): Technically, for me to make unauthorized copies of music is: (Very Easy - Very Difficult)*

(B2): If I want to, I can make unauthorized copies of music. (Strongly Agree - Strongly

Disagree)*

(B3): I can imagine times when I might make unauthorized copies of music even if I hadn't planned to. (Strongly Agree - Strongly Disagree)*

(B4): Even if I had a good reason, I could not bring myself to make unauthorized copies of music. (Strongly Agree - Strongly Disagree)

(M1): I would feel guilty if I made unauthorized copies of music. (Strongly Agree - Strongly Disagree)

(M2): Making unauthorized copies of music goes against my principles. (Strongly Agree Strongly Disagree)

(M3): It would be morally wrong for me to make unauthorized copies of music. (Strongly Agree

- Strongly Disagree)

What is your gender?

What is your age?

How often do you think you may have engaged in copying music in the last year? (Daily Never)*

Do you think most people believe copying music without paying for it is a victimless crime?

(Strongly Agree - Strongly Disagree)* 